www.nature.com/pj

\title{
Evaluating the chemio-physio properties of novel zinc oxide-polyaniline nanocomposite polymer films
}

\author{
Farah Alvi ${ }^{1,2}$, Manoj K Ram ${ }^{1}$, Humberto Gomez ${ }^{3,4}$, Rakesh K Joshi ${ }^{1,2}$ and Ashok Kumar ${ }^{1,3}$ \\ Recently, polymer matrix-based nanocomposites have become a prominent area of research and development in optics, as well \\ as in optoelectronic, biomedical, electrical and electronic applications. Organic polymer-based electronic devices have the \\ potential to be lower in cost and more flexible in the manner in which they are manufactured. However, they need significant \\ improvement in both efficiency and long-term stability. Therefore, we made an attempt to synthesize zinc oxide ( $\mathrm{ZnO}$ )- \\ polyaniline (PANI) using chemical and emulsion polymerization techniques. The properties of ZnO-PANI films were then \\ systematically characterized with several physical techniques. Electrochemical investigations revealed that the individual redox \\ properties of $\mathrm{ZnO}$ and PANI can be maintained in a nanocomposite ZnO-PANI system. Furthermore, our results indicated that \\ ZnO-PANI films can exhibit a wide redox potential window. Moreover, we observed the formation of a single-layer nano-Schottky \\ junction in ZnO-PANI films, and interesting positive temperature coefficient properties in ZnO-PANI-embedded polystyrene films. \\ Polymer Journal (2010) 42, 935-940; doi:10.1038/pj.2010.89; published online 20 October 2010
}

Keywords: electrochemistry; polymer; Schottky junction; ZnO-Polyaniline nanocomposites

\section{INTRODUCTION}

In recent years, there has been considerable interest among researchers to develop novel inorganic-organic hybrid materials with compositions modulated on the nanoscale because of their many potential applications in display technologies, microelectronics, catalysis, sensors and molecular electronics. ${ }^{1}$ The fabrication of nanocomposite films by wet chemical techniques has been proven to be a more simple and inexpensive strategy than technologically demanding physical methods. ${ }^{2}$ Recently, Ram et al. ${ }^{3-8}$ developed metal oxide and conducting polymer nanocomposite films of $\mathrm{TiO}_{2}$-PANI, $\mathrm{TiO}_{2}$-polypyrrole, $\mathrm{SnO}_{2}$-polyhexylthiophene, $\mathrm{TiO}_{2}$-poly (thiopheneaniline) nanocomposite, Mn-Ferrite-PANI and MWCNT-poly (o-anisidine) using wet chemical methods and used them extensively in gas sensing and molecular electronics applications. PANI is one of the most widely studied materials because of its unique electrochemical, chemical and physical properties. In addition, PANI exhibits high electrical conductivity and good environmental stability in both doped and pristine (undoped) states. ${ }^{9-11}$ The electronic, optical, photo-electrochemical, photoconductive, photovoltaic, thermal and sensing, for example, gas sensing and biosensing, properties of PANI could be improved by incorporating PANI with polystyrene latex, multiwalled carbon nanotubes, single-walled nanotubes, montmorillonite, graphite, $\mathrm{MCM}-41, \mathrm{TiO}_{2}$ and $\mathrm{SnO}_{2}$ micro and nanoparticles. ${ }^{9-18}$ PANI composites have also been shown to possess a variety of unique mechanical, electrical and structural properties because of synergistic effect from intimate mixing between PANI and inorganic or organic components at a molecular and an atomic level.

On the other hand, $\mathrm{ZnO}$ is a multifunctional semiconducting material with a wide band $(3.37 \mathrm{eV}$ at $300 \mathrm{~K})$ and large exciton binding energy $(60 \mathrm{MeV})$. Recently, it has been shown to exhibit several promising prospects for nanoscale structures. ${ }^{19-22}$ In fact, $1 \mathrm{D} \mathrm{ZnO}$ has been explored in a wide range of applications, such as room temperature ultraviolet (UV) lasers, surface-acoustic-wave devices, gas sensors, solar cells, infrared sensors, optoelectronic devices and electronic paper. Combining the proper energy level and high electronic mobility, $\mathrm{ZnO}$ could create a suitable material for the photo anode in dye-sensitized solar cells. ${ }^{23}$ Further, using a nanocomposite polymer scaffold, it is also possible to increase the properties of PANI, as well as of $\mathrm{ZnO}$ non-materials.

In this work, we initially prepared ZnO-PANI nanocomposite films using a wet polymerization method. Following this, we characterized ZnO-PANI by ultraviolet-visible (UV-Vis), Fourier transform infrared (FT-IR), cyclic voltammetry, impedance, scanning electron microscopy (SEM), transmission electron microscopy (TEM) and electrical conductivity. The results confirmed the presence of nano-Schottky junctions for the first time in ZnO-PANI samples.

\section{EXPERIMENTAL PROCEDURE}

Reagents and materials

Aniline (99.5\%), ammonium persulfate (98\%), sodium hydroxide (powder, $97 \%)$ and hydrochloric acid (37\%) were all of ACS grade and purchased from

\footnotetext{
${ }^{1}$ Nanomaterials and Nanomanufacturing Research Center, University of South Florida, Tampa, FL, USA; ${ }^{2}$ Department of Electrical Engineering, University of South Florida, Tampa, FL, USA; ${ }^{3}$ Department of Mechanical Engineering, University of South Florida, Tampa, FL, USA and ${ }^{4}$ Departamento de Ingenieria Mecanica, Universidad del Norte, Barranquilla, Colombia

Correspondence: Dr F Alvi, Department of Electrical Engineering, University of South Florida, 4202 E Fowler Avenue, Tampa, FL 33620-5350, USA

E-mail: falvi@mail.usf.edu

Received 17 May 2010; revised 5 August 2010; accepted 12 August 2010; published online 20 October 2010
} 
Sigma-Aldrich (St Louis, MO, USA). N-N-dimethylformamide (99.8\%) was purchased from Alfa Aesar (Somerville, MA, USA). ZnO nanoparticles (99.8\%, diameter 10-30 nm) were purchased from SRY spring nanomaterials (Houston, TX, USA). All these chemicals and materials were used as purchased without any further purification unless specified.

\section{Synthesis of $\mathrm{ZnO}-\mathrm{PANI}$ nanocomposite conducting polymer}

ZnO-PANI nanocomposites were chemically synthesized by the oxidative polymerization of aniline using ammonium peroxydisulfate $\left.\left[\left(\mathrm{NH}_{4}\right)_{2} \mathrm{~S}_{2} \mathrm{O}_{8}\right)\right]$ under controlled conditions. ${ }^{24-26}$ The aniline to $\mathrm{ZnO}$ ratios were kept to $1: 1$, 3:1 or 1:3, with added $1.0 \mathrm{M} \mathrm{HCl}$. This mixture was then cooled down to $4{ }^{\circ} \mathrm{C}$ in an ice bath. Next, ammonium peroxydisulfate $(0.025 \mathrm{M})$ was dissolved in $200 \mathrm{ml}$ of $1.0 \mathrm{M} \mathrm{HCl}$ solution and cooled to $4^{\circ} \mathrm{C}$. Later, $\left.\left[\left(\mathrm{NH}_{4}\right)_{2} \mathrm{~S}_{2} \mathrm{O}_{8}\right)\right]$ in $1.0 \mathrm{M} \mathrm{HCl}$ solution was added in drops to the above-mentioned aniline solution. The reaction was allowed to continue for $12 \mathrm{~h}$. The dark green precipitate of the $\mathrm{ZnO}-\mathrm{PANI}$ nanocomposite recovered from the reaction vessel was then filtered and washed using $1.0 \mathrm{M} \mathrm{HCl}$ (to remove any oxidant and oligomers). This precipitate was further washed using distilled water, methanol and diethyl ether to eliminate low-molecular-weight polymer and oligomers. This precipitate was then heated at $100^{\circ} \mathrm{C}$ for $6 \mathrm{~h}$ in a temperature-controlled oven. The dark blue powder thus obtained was the emeraldine base form of the ZnO-PANI conducting polymer, which was used in spin coating and casting of films. A schematic of the synthesized ZnO-PANI nanocomposite material is shown in Figure 1 .

\section{Optical Characterizations of LS Films}

The ZnO-PANI thus obtained was deposited on a Si [111] wafer and doped in $1.0 \mathrm{M} \mathrm{HCl}$. Following this, the UV-Vis spectra of ZnO-PANI deposited on glass or quartz were obtained using a UV-Vis Spectrometer (Jasco V-530, Jasco, Tokyo, Japan). Next, the ZnO-PANI film (doped) was characterized for its different vibrational bands with a FT-IR spectrophotometer (Perkin-Elmer, Shelton, CT, USA). The sample chamber of the spectrophotometer was continuously purged with nitrogen for 15-20 min before data collection and during the determination of measurements for the elimination of water vapor. For each sample, eight interferograms were recorded, averaged and Fourier transformed to produce a spectrum with a nominal resolution of $4 \mathrm{~cm}$. Finally, the FT-IR spectra of ZnO-PANI nanocomposite films were obtained after proper subtraction using a silicon substrate baseline.

\section{Electrical measurements}

The current-voltage (I-V) characterization of ZnO-PANI was performed using a Keithley electrometer (model 6517, Keithley, Hayward, CA, USA), together with an operational amplifier in the inverted configuration. Before taking the measurements, the $\mathrm{ZnO}-\mathrm{PANI}$ film was deposited on a glass plate and a thin silver wire was connected to the $\mathrm{ZnO}-\mathrm{PANI}$ nanocomposite film using silver paste. Different ratios of aniline to $\mathrm{ZnO}$ resistance measurement are shown in Table 1. The film was heated in controlled conditions and the corresponding I-V characteristics were measured (otherwise known as a positive temperature coefficient).

\section{Surface characterization}

The surface morphology and size of ZnO-PANI films were then investigated by field emission SEM (JEOL 6340F microscope (JEOL, Newark, NJ, USA), operated at $5 \mathrm{kV}$ ). Following this, the $\mathrm{ZnO}-\mathrm{PANI}$ nanocomposites were investigated using high-resolution TEM (JEOL 3011 microscope, operated at $300 \mathrm{kV}$ ).

\section{RESULTS}

\section{Optical characterizations}

Optical spectroscopy of conducting polymers is the preferred tool for gathering information about the absorption bands of inter- and intra-gap states.

UV-Vis spectroscopy. The UV-Vis absorption spectra of native $\mathrm{ZnO}$, $\mathrm{ZnO}$ (doped in $\mathrm{HCl}$ ), $\mathrm{ZnO}-\mathrm{PANI}$ (undoped) and $\mathrm{ZnO}-\mathrm{PANI}$ (doped) were obtained and are shown in Figure 2. In Figure 2a, the onset of absorption at $330 \mathrm{~nm}$ corresponds to $\pi-\pi^{*}$ transition related to the energy difference between the valence band to the conduction band. The origin of the band at $523 \mathrm{~nm}$ is associated with defect-related states located within the bandgap of $\mathrm{ZnO}$. On the other hand, doping of $\mathrm{ZnO}$ in $\mathrm{HCl}$ resulted in absorption bands at 337 and $386 \mathrm{~nm}$ and a broad band between 410 and $1000 \mathrm{~nm}$ because of the dopant effect. ${ }^{27,28} \mathrm{Next}$, the UV-Vis spectra of ZnO-PANI exhibited bands at 330 and $620 \mathrm{~nm}$ because of the $\pi-\pi^{*}$ and $n-\pi^{*}$ transitions, respectively. On protonation, the band observed at $330 \mathrm{~nm}$ in the UV-Vis spectra of ZnO-PANI shifted to $370 \mathrm{~nm}$ (Figure 2d). In addition to this shift, protonated $\mathrm{ZnO}-\mathrm{PANI}$ also exhibited absorption bands from 700 to $1000 \mathrm{~nm}$ as a result of protonation (Figure 2d).

Table 1 Resistance measurements for $\mathrm{ZnO}$-polyaniline (PANI) (doped in $1.0 \mathrm{M} \mathrm{HCl}$ )

\begin{tabular}{lcc}
\hline Aniline (ratio) & ZnO (ratio) & Resistance of ZnO-PANI \\
\hline 1 & 1 & 40.7 \\
2 & 1 & $20.7 \mathrm{k} \Omega$ \\
1 & 2 & $100 \mathrm{k} \Omega$ \\
\hline
\end{tabular}

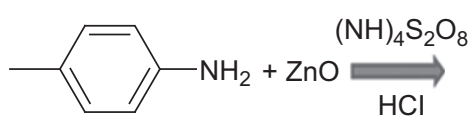

Oxidative Polymerization
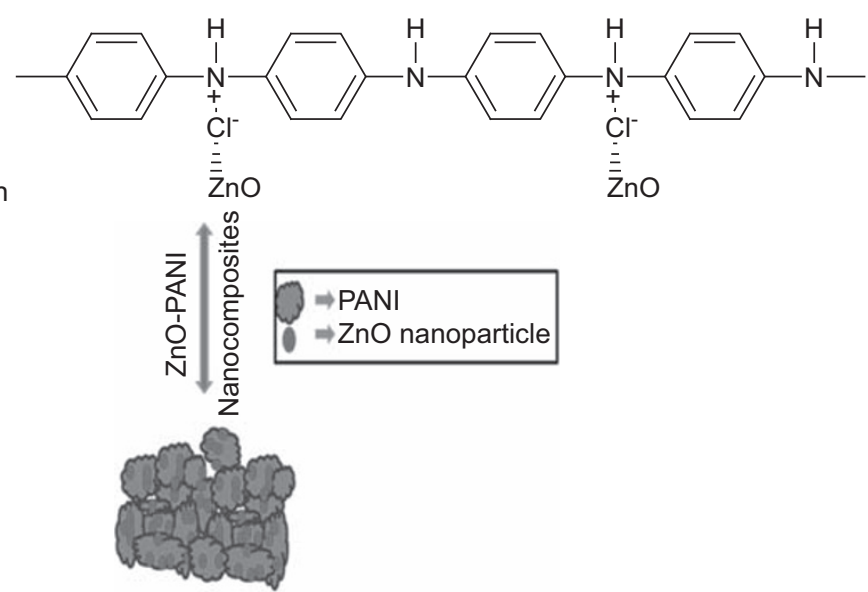

Figure 1 Synthesis of zinc oxide (ZnO)-polyaniline (PANI) nanocomposite material. 


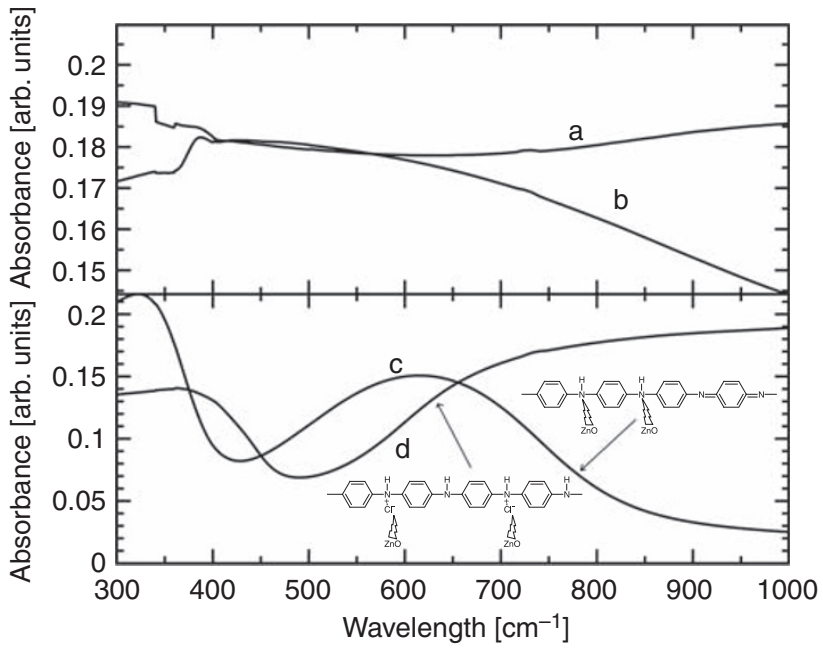

Figure 2 Ultraviolet-visible spectra of films on quartz (a) $\mathrm{ZnO}$ (undoped), (b) ZnO (doped), (c) ZnO-polyaniline (PANI) (undoped) and (d) ZnO-PANI (doped) in $\mathrm{HCl}$.

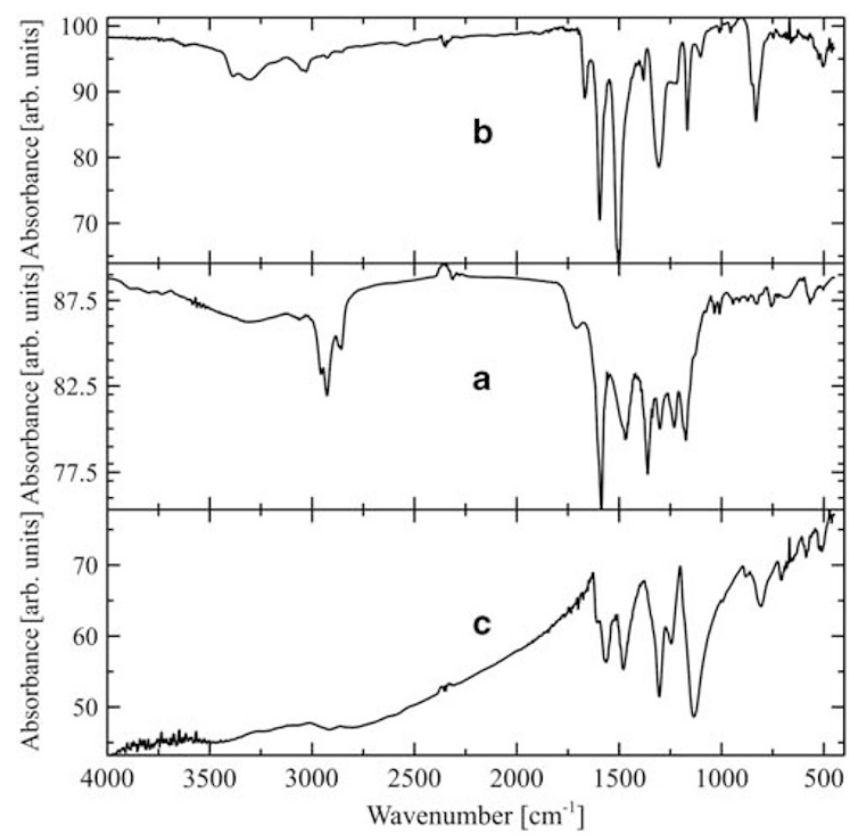

Figure 3 Fourier transform infrared spectra of (a) $\mathrm{ZnO}$, (b) ZnO-polyaniline (PANI) (undoped) and (c) ZnO-PANI (doped) films.

FT-IR spectroscopy. Figures 3a-c depict the FT-IR spectra of native $\mathrm{ZnO}, \mathrm{ZnO}-\mathrm{PANI}$ (undoped) and $\mathrm{ZnO}-\mathrm{PANI}$ (doped in $1 \mathrm{M} \mathrm{HCl}$ ) coated on a silicon substrate, respectively. As is evident from Figure 3a, the FT-IR spectrum of $\mathrm{ZnO}$ exhibited its characteristic bands at 2926, $2800,1586,1471,1360,1173$ and $831 \mathrm{~cm}^{-1}$. Of these bands, the band at $1360 \mathrm{~cm}^{-1}$ is the characteristic band of $\mathrm{ZnO}$ nanoparticles, and the band at $2800 \mathrm{~cm}^{-1}$ is attributed to the $\mathrm{O}-\mathrm{H}$ stretching present within the $\mathrm{ZnO}$ nanoparticles. On the other hand, the FT-IR spectra of $\mathrm{ZnO}-$ PANI (undoped) exhibited characteristic bands at 3390, 3297, 3028, $1668,1594,1504,1380,1306,1212,1167,1102,1004,949,831,661$ and $504 \mathrm{~cm}^{-1}$. Among these, the band at $3390 \mathrm{~cm}^{-1}$ is due to the N-H stretching of PANI in $\mathrm{ZnO}-\mathrm{PANI}$ (undoped). The appearance of peaks at 1594 and $1504 \mathrm{~cm}^{-1}$ is attributed to the $\mathrm{C}=\mathrm{C}$ stretching of quinoid
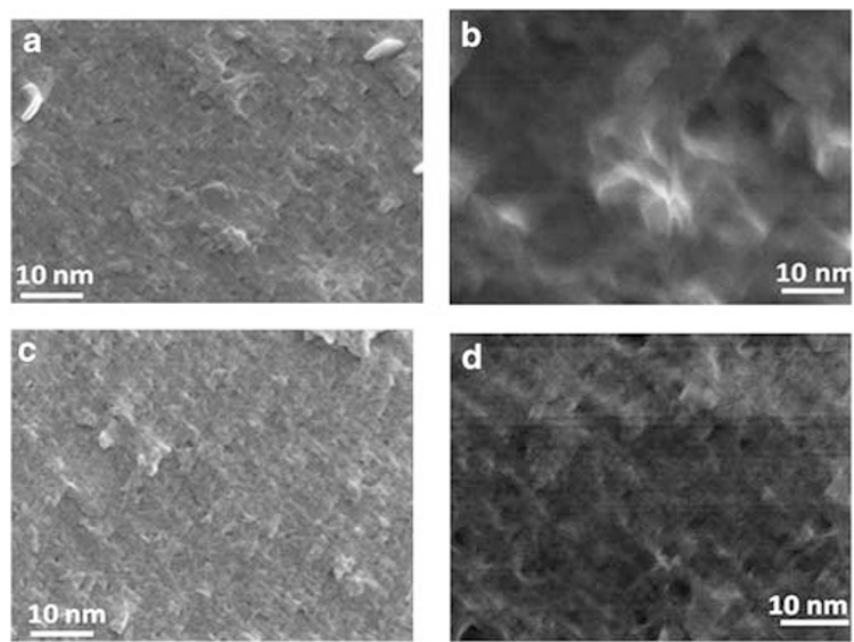

Figure 4 Scanning electron microscopy images of (a) ZnO-polyaniline (PANI) nanocomposite films (undoped), (b) ZnO-PANI nanocomposite films (doped), (c) ZnO-PANI nanocomposite films (undoped) on silicon substrates and (d) calibartion plot of ZnO-PANi film deposited on ITO.

and benzenoid rings, respectively. The band at $1303 \mathrm{~cm}^{-1}$ is assigned to the emeraldine base structure. Further, the band at $1167 \mathrm{~cm}^{-1}$ is due to $\mathrm{N}=\mathrm{Q}=\mathrm{N}$, where $\mathrm{Q}$ represents the quinoid ring present in the $\mathrm{ZnO}-\mathrm{PANI}$ nanocomposite (undoped). The band at $3028-3297 \mathrm{~cm}^{-1}$ is assigned to $\mathrm{C}-\mathrm{H}$ stretching of PANI. As shown in Figure $3 \mathrm{c}$, the $\mathrm{ZnO}$-PANI (doped) form exhibited characteristic bands at 3445, $3197,2910,2780,1605,1563,1478,1303,1245,1133,800,803,702$, 587 and $502 \mathrm{~cm}^{-1}$. Of these, the prominent bands at 1303 and $1245 \mathrm{~cm}^{-1}$ can be attributed to $\mathrm{C}-\mathrm{N}^{+}$stretching of doped PANI. ${ }^{29}$ It is very interesting to note that the band observed at $1380 \mathrm{~cm}^{-1}$ in $\mathrm{ZnO}-\mathrm{PANI}$ (undoped) is shifted to $1303 \mathrm{~cm}^{-1}$ in the $\mathrm{ZnO}-\mathrm{PANI}$ (doped) as a result of protonation. In addition, the peak observed at $2800 \mathrm{~cm}^{-1}$ in $\mathrm{ZnO}$ was not observed in $\mathrm{ZnO}-\mathrm{PANI}$ (undoped) and $\mathrm{ZnO}-\mathrm{PANI}$ (doped) because of the presence of the $\mathrm{N}-\mathrm{H}$ group in the PANI molecular chain itself.

\section{Surface characterization}

The morphologies of $\mathrm{ZnO}-\mathrm{PANI}$ nanocomposite films were examined by field emission SEM and TEM. Before determining the surface measurements, $\mathrm{ZnO}-\mathrm{PANI}$ films were uniformly deposited on the $\mathrm{Si}$ [111] surface.

SEM of $\mathrm{ZnO}-P A N I$. Figures $4 \mathrm{a}$ and $\mathrm{b}$ show SEM images of a $\mathrm{ZnO}-$ PANI nanocomposite film (undoped). Of these, Figure $4 \mathrm{~b}$ has the higher magnification and indicates a rock salt structure embedded within the polymeric structure that is entirely different from the PANI film observed by Ram et al. ${ }^{29}$ On the other hand, Figures $4 \mathrm{c}$ and $\mathrm{d}$ show the SEM images of an aligned $\mathrm{ZnO}-\mathrm{PANI}$ nanocomposite film (doped) that is uniform along the axis. However, ZnO-PANI composite films fabricated using different proportions of $\mathrm{ZnO}$ and aniline exhibited identical structures (figure not shown). On comparison, the surface structure of $\mathrm{ZnO}-\mathrm{PANI}$ (doped), as shown in Figures $4 \mathrm{c}$ and $\mathrm{d}$, is similar to that of $\mathrm{ZnO}-\mathrm{PANI}$ (undoped) shown in Figure 4a. However, at higher resolution, ZnO-PANI (doped) exhibited a different structure because of the structural orientation of PANI in the doped state. The average diameter and height of $\mathrm{ZnO}-\mathrm{PANI}$ grains were found to be 30 and $130 \mathrm{~nm}$, respectively.

TEM of ZnO-PANI. TEM micrographs of the $\mathrm{ZnO}, \mathrm{ZnO}-\mathrm{PANI}$ (undoped) and $\mathrm{ZnO}-\mathrm{PANI}$ (doped) nanoparticles are shown in 
Figures $5 \mathrm{a}, \mathrm{b}$ and $6 \mathrm{a}$, respectively. From the TEM images, it is evident that the average diameter of the $\mathrm{ZnO}$ nanoparticles is about $10 \mathrm{~nm}$. Further, the TEM of the ZnO-PANI (undoped) (Figure 5b) shows that the $\mathrm{ZnO}$ nanoparticles are encapsulated within the PANI polymeric structures. The ZnO-PANI particle size is $30-50 \mathrm{~nm}$, which is larger than that of the $\mathrm{ZnO}$ nanoparticle precursor, indicating that polymerization occurs by aggregation of a few nanoparticles. Moreover, for the first time, we have reported a TEM image of $\mathrm{ZnO}-\mathrm{PANI}$ (doped), which is shown in Figure 6b.

\section{Electrochemical characterization}

Figure $7 \mathrm{a}$ shows the cyclic voltammogram of $\mathrm{ZnO}$ deposited on an indium tin oxide plate that was performed in $1.0 \mathrm{M} \mathrm{HCl}$. The $\mathrm{ZnO}$ shows oxidation peaks at $0.5,0.14$ and $0.5 \mathrm{~V}$, and a reduction peak at $0.5 \mathrm{~V}$. The peak at $0.5 \mathrm{~V}$ corresponds to anodic dissolution, and one at $-0.5 \mathrm{~V}$ corresponds to the reduction of zincate. Such peaks have already been observed by Renuka et al. ${ }^{30}$ Such redox characteristics in $\mathrm{ZnO}$ are due to controlled nucleation of $\mathrm{ZnO}$ in the redox systems.

Following this, cyclic voltammetry of $\mathrm{ZnO}-\mathrm{PANI}$ was also performed in $1.0 \mathrm{M} \mathrm{HCl}$. The corresponding voltammogram is shown in Figure 7b. The cyclic voltammogram of ZnO-PANI exhibited a pair of reversible redox peaks at 0.14 and $0.7 \mathrm{~V}$. The peak centered at $0.14 \mathrm{~V}$ is attributed to oxidation of the emeraldine form of PANI, whereas the peak at $0.7 \mathrm{~V}$ is due to the pernigraniline form of PANI (otherwise known as protonation of PANI). ${ }^{31}$ However, the peak at $-0.5 \mathrm{~V}$ can be attributed to the oxidation of $\mathrm{ZnO}$ in the acidic medium. Interestingly, from Figure $7 \mathrm{~b}$, it is obvious that the $\mathrm{ZnO}-\mathrm{PANI}$ nanocomposite exhibited distinct redox peaks of $\mathrm{ZnO}$ (at $-0.5 \mathrm{~V}$ ) and PANI (at 0.14 and $0.7 \mathrm{~V}$ ) because of the incorporation of PANI into $\mathrm{ZnO}$. From these
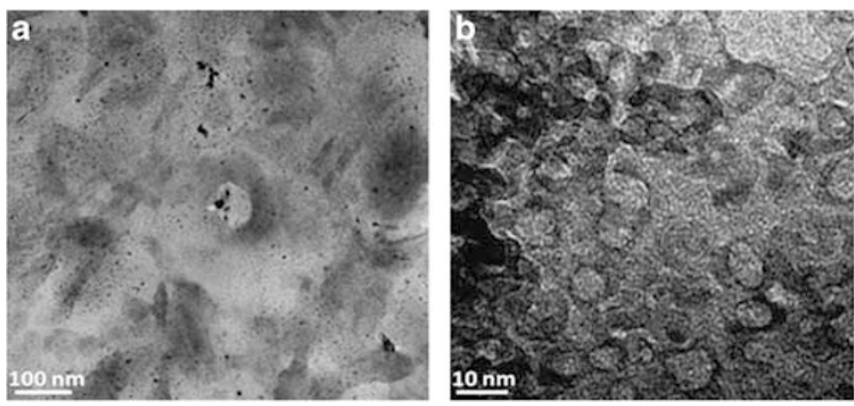

Figure 5 Transmission electron microscopy of (a) ZnO nanoparticles and (b) ZnO-polyaniline nanocomposite films on silicon substrates.
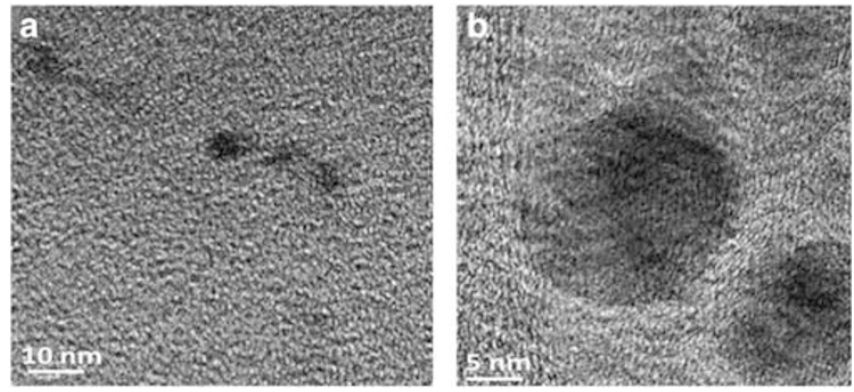

Figure 6 (a) Transmission electron microscopy (TEM) of $\mathrm{ZnO}$-polyaniline (PANI) nanocomposite films on a silicon substrate (doped), (b) highresolution TEM image of a ZnO-PANI nanocomposite film on a silicon substrate. results, one can see that the $\mathrm{ZnO}-\mathrm{PANI}$ nanocomposite exhibits its individual characteristic voltammetric signature at the appropriate potential, thereby retaining $\mathrm{ZnO}-\mathrm{PANI}$ individual redox characteristics expressed in Table 2. Further, the plot of the square root of scan rate versus current density was found to be linear (in the case of $\mathrm{ZnO}-\mathrm{PANI}$ ), indicating a diffusion-controlled process at $\mathrm{ZnO}-\mathrm{PANI}$ electrodes. ${ }^{32}$ Moreover, on the basis of the Randles-Sevick equation, the diffusion coefficient $\left(\mathrm{D}^{\circ}\right)$ of $1.0 \mathrm{M} \mathrm{HCl}$ at the $\mathrm{ZnO}-\mathrm{PANI}$ electrode was calculated to be $0.7 \times 10^{-10} \mathrm{~cm}^{2} \mathrm{~s}^{-1}$. This value is almost three times smaller than the $\mathrm{D}^{\circ}$ obtained with $\mathrm{ZnO}-\mathrm{PANI}$ (undoped). In addition, chronoamperometric experiments conducted using these $\mathrm{ZnO}-\mathrm{PANI}$ electrodes in $0.1 \mathrm{M} \mathrm{HCl}$ (Figure 8) indicated that $\mathrm{ZnO}-\mathrm{PANI}$ exhibited a rapid response $(<2 \mathrm{~s})$.

To further investigate the electron transfer properties at the $\mathrm{ZnO}-\mathrm{PANI}$ interface, we used electrochemical impedance spectroscopy. Electrochemical impedance spectroscopy of $\mathrm{ZnO}-\mathrm{PANI}$ was performed in $0.1 \mathrm{M} \mathrm{HCl}$ (vs $\mathrm{Ag} \mid \mathrm{AgCl}$ ). The corresponding Nyquist plot is shown in Figure 9. The Nyquist plot of the ZnO-PANI composite depicts well-defined frequency-dependent semicircle impedance a

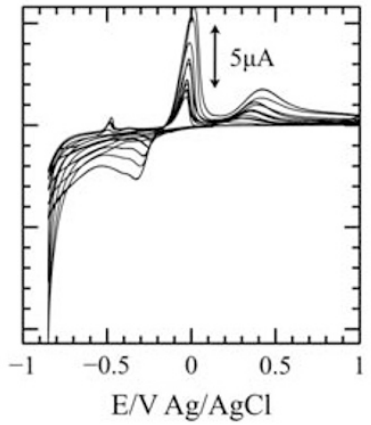

C

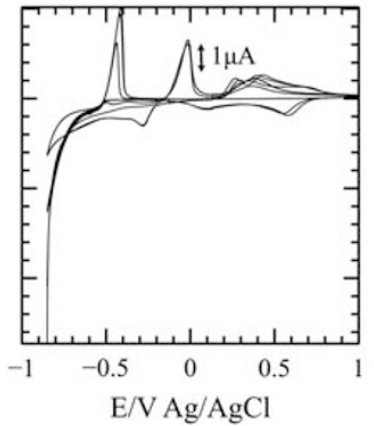

b

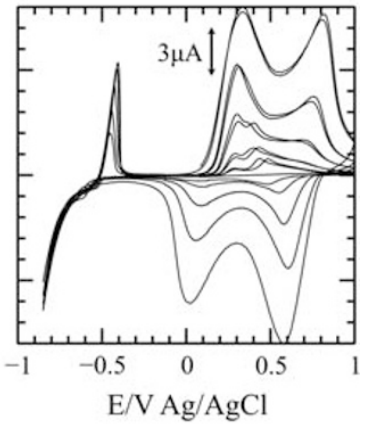

d

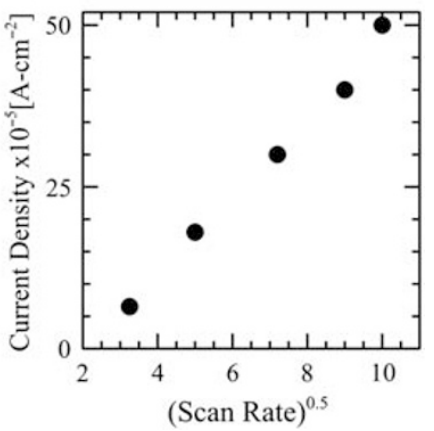

Figure 7 Cyclic voltammogram of (a) $\mathrm{ZnO}$ nanoparticles, (b) $\mathrm{ZnO}$-polyaniline (PANI) (undoped) and (c) ZnO-PANI (doped in $1.0 \mathrm{~m} \mathrm{HCl}$ ) deposited on an indium tin oxide plate at different scan rates. (d) Calibration plot of ZnO-PANI film deposited on indium tin oxide.

Table 2 Redox potentials of $\mathrm{ZnO}$, polyaniline (PANI) and ZnO-PANI thin films in $0.1 \mathrm{~m} \mathrm{HCl}$ (scan rate: $50 \mathrm{mV} \mathrm{s}^{-1}$ )

\begin{tabular}{lcc}
\hline & Oxidation potential $(V)$ & Reduction potential (V) \\
\hline ZnO & $-0.5,0.14,0.5$ & -0.5 \\
PANI & $0.6,0.4,0.2$ & $0.6,0.36,0.48$ \\
ZnO-PANI & 0.14 and 0.7 & -0.6 and -0.4 \\
\hline
\end{tabular}




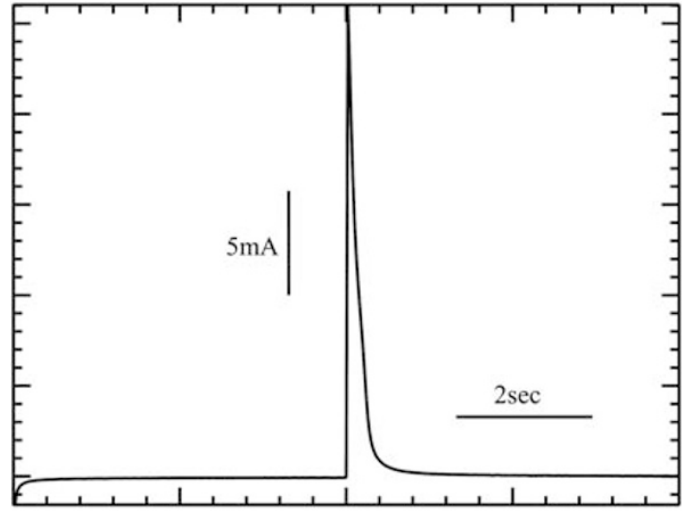

Time [s]

Figure 8 Chronoamperometry of $\mathrm{ZnO}-$ polyaniline in $1.0 \mathrm{~m} \mathrm{HCl}$.

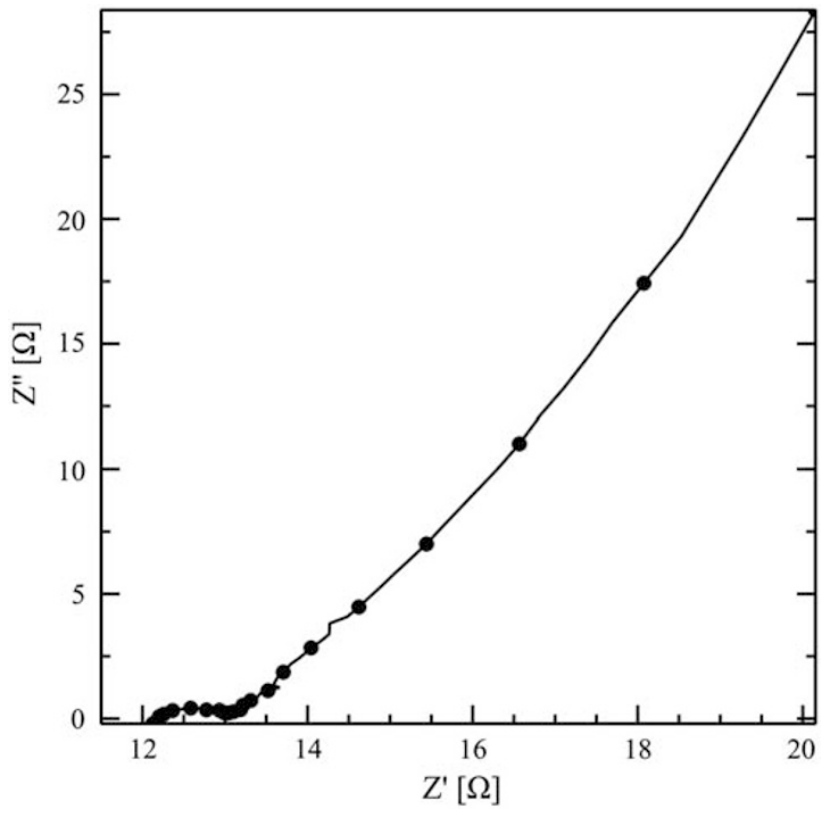

Figure 9 Nyquist plot of a $\mathrm{ZnO}$-polyaniline nanocomposite film coated on an indium tin oxide glass plate in $1.0 \mathrm{~m} \mathrm{HCl}$ (vs $\mathrm{Ag} / \mathrm{AgCl}$ ).

curves over high frequencies, followed by straight lines. The linear part in the plot is attributed to the polarization resistance of the $\mathrm{ZnO}-$ PANI (doped) electrodes, which is diffusion resistance. Further, the smaller semicircle observed is an indication of a faster electrontransfer rate. Moreover, it is evident from Figure 9 that the presence of $\mathrm{ZnO}$ showed behavior typical of any redox species occurring because of the presence of PANI.

Electrical measurement. In this work, the formation of a simple single-layer hybrid of a $\mathrm{ZnO}$ and PANI-based diode structure has been reported for the first time. To study its behavior, the I-V characteristics of $\mathrm{ZnO}-\mathrm{PANI}$ nanocomposite films were measured. To perform the I-V studies, a ZnO-PANI nanocomposite film was deposited on a glass slide and doped with $1.0 \mathrm{M} \mathrm{HCl}$. Figure 10 shows the representative $\mathrm{I}-\mathrm{V}$ characteristics of the $\mathrm{ZnO}-\mathrm{PANI}$ used in this work. During the forward and reverse bias conditions, the I-V characteristics of the Al/ZnO-PANI heterojunctions exhibited a

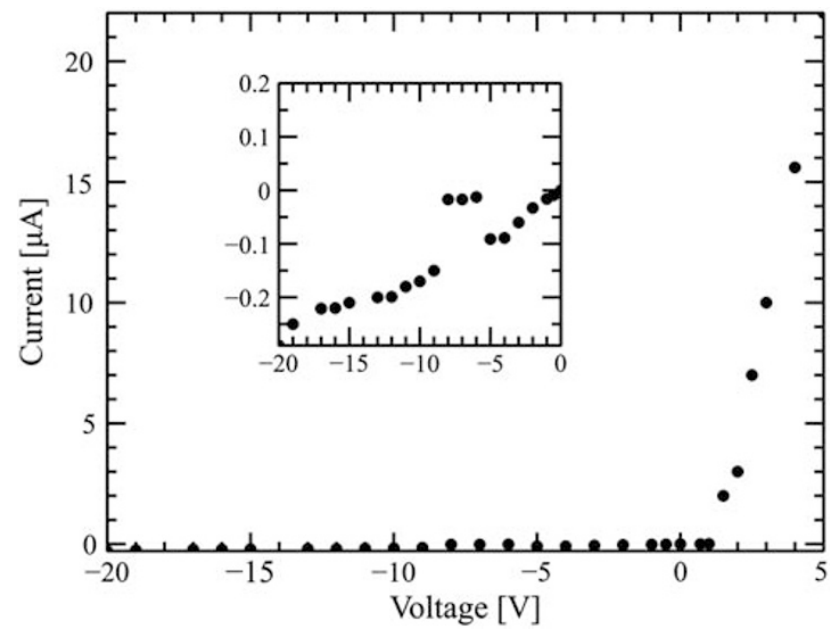

Figure $10 \mathrm{I}-\mathrm{V}$ characteristics of a $\mathrm{ZnO}-$ polyaniline junction.

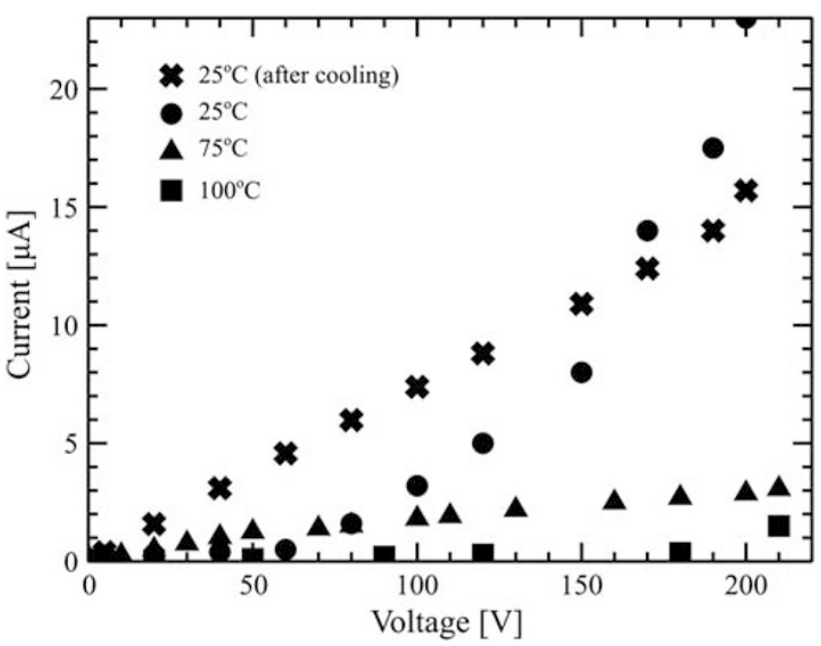

Figure 11 The positive temperature coefficient measurements of $\mathrm{ZnO}$ polyaniline-polystyrene films as a function of temperature.

build-up of space charge at the interface. However, rectification was obtained in $\mathrm{Al} / \mathrm{ZnO}-\mathrm{PANI}$ at $1.0 \mathrm{~V}$, measured at the planar surface. The I-V characteristics of the ZnO-PANI nanocomposite indicated a rectifying behavior, as shown in Figure 10, with an $I_{\mathrm{F}} / I_{\mathrm{R}}$ value of 241, where $I_{\mathrm{F}}$ and $I_{\mathrm{R}}$ represent the forward and reverse current, respectively, indicating the formation of a diode between hybrid ZnO-PANI nanocomposites with Al. Further, to calculate the ideality factor, we used the following standard diode equation:

$$
I=I_{\mathrm{s}}[\exp (q V / n k T-1)]
$$

here ' $q$ ' is the electronic charge, ' $V$ ' is the applied voltage, ' $k$ ' is the Boltzmann constant, ' $n$ ' is the ideality factor and ' $I_{s}$ ' is the saturation current. On calculation, the ideality factor ' $n$ ' for the device was found to be 0.25 . This smaller ' $n$ ' value indicates that the diode is not an ideal one. This is probably due to the presence of surface states in $\mathrm{ZnO}-\mathrm{PANI}$ and defects at the film interface.

Figure 11 shows the (I-V) characteristics of $\mathrm{ZnO}-\mathrm{PANI}$ embedded in polystyrene polymer as a function of temperature. The resistance of the film was found to increase with an increase in temperature, as shown in Figure 11. Cooling of the film shows reversible behavior in 
ZnO-PANI-polystyrene. This study reveals interesting positive temperature coefficient properties in $\mathrm{ZnO}-\mathrm{PANI}-$ polystyrene films for thermal application.

\section{CONCLUSION}

In this work, we successfully demonstrated the formation of organicinorganic nanostructures using $\mathrm{ZnO}$ and aniline monomer. $\mathrm{ZnO}-\mathrm{PANI}$ nanocomposites were successfully synthesized using an in situ polymerization technique. From experiments, it is obvious that the longorder integrity of $\mathrm{ZnO}$ and PANI remains intact after encapsulation of $\mathrm{ZnO}$ with PANI-conducting polymer. FT-IR spectra of the ZnO-PANI nanocomposite indicated that the presence of $\mathrm{ZnO}$ has profound effects on the emeraldine form to emeraldine salt state. The electrochemical results revealed that $\mathrm{ZnO}$ and PANI redox properties can be studied at a wider potential range. Moreover, for the first time, we observed a Schottky diode and positive temperature coefficient behavior in a planar $\mathrm{ZnO}-\mathrm{PANI}$ film. Further, this work opens up a new avenue for the use of $\mathrm{ZnO}-\mathrm{PANI}$ as a Schottky diode and positive temperature coefficient for numerous applications, including relay applications.

1 Lehn, J. M., Fendler, J. H. \& Meldrum, F. The colloid chemical approach to nanostructured materials. Adv. Mater 7, 607-632 (1995).

2 Alivisatos, P. Electrical studies of semiconductor-nanocrystal colloids. MRS Bull 23, 18-23 (1998).

3 Ram, M. K., Yavuz, O., Lahsangah, V. \& Aldissi, M. CO gas sensing ultrathin nanocomposite conducting polymer. Sens. and Actuat. B. 106, $750-757$ (2005).

4 Ram, M. K., Yavuz, O. \& Aldissi, M. NO2 gas sensing based on ordered ultrathin films of conducting polymer and its nanocomposite. Syn. Met. 151, 77-79 (2005).

5 Yavuz, O., Ram, M. K., Aldissi, M., Poddar, P. \& Srikanth, H. Synthesis and the physical properties of $\mathrm{MnZn}$ ferrite and NiMnZn ferrite-polyaniline nanocomposite particles. J. Mater. Chem. 15, 810-817 (2005).

6 Yavuz, O., Ram, M. K. \& Aldissi, M. The new frontiers of organic and composite nanotechnology. In Electromagnetic Applications of Conducting and Nanocomposite Materials Vol. 14, 35-37 (Elsevier, Fractal System Inc., Safety Harbor, FL, USA, 2008).

7 Ram, M. K., Salerno, M., Adami, M., Faraci, P. \& Nicolini, C. Physical properties of polyaniline films: Assembled by the layer by layer technique. Langmuir 15, 1252-1259 (1999).

8 Bavastrello, V., Carrara, S., Ram, M. K. \& Nicolini, C. Nanometer size polymer based Schottky composite Langmuir-Schaefer films. Langmuir. 20, 969-973 (2004).

9 Bavastrello, V., Ram, M. K. \& Nicolini, C. Fabrication and characterization of its Langmuir schaefer films. Langmuir. 18, 1535-1541 (2002).

10 Yavuz, O., Ram, M. K. \& Aldissi, M. Colloidal Nanoparticles in Biotechnology 223-245 (John Wiley \& Sons, Inc, 2008).

11 Wessling, B., Cesar, B., Horacio, S., Diego, A., Doris, G. \& Fernando, G. Progress in science and technology of polyanlinie and poly-ethylenedioxythiophene. Synth. Met. $135,265-267$ (2003).
12 Chang, M., Cao, X. \& Haibo, Z. Electrodeposition growth of vertical ZnO nanorod/ polyaniline heterostructured films and their optical properties. J. Phys. Chem. C. 113, 15544-15547 (2009).

13 Kovtyukhova, N., Olivier, P. J., Chizhik, S., Dubravin, A., Buzaneva, E., Gorchinskiy, A., Marchenko, A. \& Smirnova, N. Self-assembly of ultrathin composite TiO2/polymer films. Thin Solid Films 337, 166-170 (1999).

14 Fendler, J. Self-Assembled nanostructured materials. Chem. Mater. 8, 1616-1624 (1996).

15 Ollivier, P. J., Kovtyukhova, N. I., Keller, S. W. \& Mallouk, T. E. Self-assembled thin films from lamellar metal disulfides and organic polymers. Chem. Comm. 15, 1563-1564 (1998).

16 Schmitt, J., Decher, G., Dressick, W., Brandow, S. L., Geer, R. E., Shashidhar, R. \& Calvert, J. M. Metal nanoparticle/polymer superlattice films: fabrication and control of layer structure. Adv. Mater. 9, 61-65 (1997).

17 Kotov, N. A., Dekany, I. \& Fendler, J. H. Layer-by-layer self-assembly of polyelectrolytesemiconductor nanoparticle composite films. J. Phys. Chem. 99, 13065-13069 (1995).

18 Kotov, N. A., Dekany, I. \& Fendler, J. H. Ultrathin graphite oxide-polyelectrolyte composites prepared by self-assembly: transition between conductive and non-conductive states. Adv. Mate. 8, 637-641 (1996).

19 Yoichiro, N., Aki, M., Hiroko, K., Toru, A., Yoshinori, H. \& Goro, S. Preparation of ZnO thin films for high-resolution field emission display by electron beam evaporation. Appl. Surf. Sci. 142, 233-236 (1999).

20 Ning, G. H., Zhao, X. P., Li, J. \& Zhang, C- Q. Hugely enhanced electroluminescence from mesoporous ZnO particles. Opt. Mater. 28, 385-390 (2006).

21 Li, Q., Kumar, V., Li, Y., Zhang, H., Marks, T. J. \& Chang, R. P. H. Fabrication of ZnO nanorods and nanotubes in aqueous solutions. Chem. Mater. 17, 1001-1006 (2005).

22 Xu, Z. X., Roy, V. A. L., Stallinga, P., Toffanin, M., Xiang, H. F. \& Che, C. M. Nanocomposite field effect transistors based on zinc oxide/polymer blends. Appl. Phys. Lett. 90, 223509-2740478 (2007).

23 Gustafsson, G., Cao, Y., Treacy, G. M., Klavetter, F., Colaneri, N. \& Heeger, A. Flexible light-emitting diodes made from soluble conducting polymers. Nature 357, 477-479 (1992).

24 Sailor, M. J., Ginsburg, E. J., Gorman, C. B., Kumar, A., Grubbs, R. H. \& Lewis, N. S. Thin films of n-Si/Poly- $\left(\mathrm{CH}_{3}\right)_{3}$ Si-Cyclooctatetraene: conducting-polymer solar cells and layered structures. Science 249, 1146-1149 (1990).

25 Kovtyukhova, N. I., Gorchinskiy, A. D. \& Waraksa, C. Self-Assembly of nanostructured composite ZnO/Polyaniline films. Mater. Sci. Eng. B. 424, 69-70 (2000).

26 Yongjun, H. E. A novel emulsion route to sub-micrometer polyaniline/nano-ZnO composite fibers. Appl. Surface Sci. 249, 1-6 (2005).

27 Oliveira, A. P. A., Hoch pied, J. F., Grillon, F. \& Berger, M. H. Controlled precipitation of zinc oxide particles at room temperature. Chem. Mater. 15, 3202-3207 (2003).

28 McBride, R. A., Kelly, J. M. \& MeCormack, D. E. Growth of well-defined ZnO microparticles by hydroxide ion hydrolysis of zinc salts. J. Mater. Chem. 13, 1196-1201 (2003).

29 Ram, M. K., Maccioni, E. \& Nicolini, C. The electro chromic response of polyaniline and its copolymeric systems. Thin Solid Films 303, 27-33 (1997).

30 Renuka, R., Srinivasan, L., Ramamurthy, S., Veluchamy, A. \& Venkatakrishnan, N. Cyclic voltammetric study of zinc and zinc oxide electrodes in $5.3 \mathrm{M} \mathrm{KOH}$. J. Appl. Electrochem. 31, 655-661 (2001).

31 Woo, H. S., Czerw, R., Webster, S., Carroll, D. L., Park, J. W. \& Lee, J. H. Organic light emitting diodes fabricated with single wall carbon nanotubes dispersed in a hole conducting buffer: the role of carbon nanotubes in a hole conducting polymer. Synth. Met. 116, 369-372 (2001).

32 Stephan, C., Nguyen, T. P., Lefrant, S., Journet, C. \& Bernier, P. Characterization of single walled carbon nanotubes-PMMA composites. Synth. Met. 108, 139-149 (2000). 